Dokuz Eylül Üniversitesi-Mühendislik Fakültesi

Fen ve Mühendislik Dergisi

Cilt 20, Sayı 60, Eylül, 2018
Dokuz Eylul University-Faculty of Engineering Journal of Science and Engineering Volume 20, Issue 60, September, 2018

DOI: $10.21205 /$ deufmd. 2018206066

\title{
Farklı Karakteristikli Piezoelektrik Algılayıcıların Dinamik Performanslarının Karşılaştırılması
}

\author{
Levent MALGACA*1, Mehmet UYAR ${ }^{2}$ \\ ${ }^{1}$ Dokuz Eylül Üniversitesi, Mühendislik Fakültesi, Makine Mühendisliği Bölümü, 35397, İzmir \\ (ORCID: 0000-0003-2019-8758) \\ ${ }^{2}$ Bayburt Üniversitesi, Mühendislik Fakültesi, Makine Mühendisliği Bölümü, 69000, Bayburt
} (ORCID: 0000-0003-3511-7682)

(Alınış / Received: 05.02.2018, Kabul / Accepted: 07.05.2018, Online Yayınlanma / Published Online: 15.09.2018)

Anahtar Kelimeler Özet: Günümüzde piezoelektrik malzemeler algılayıcı veya uyarıcı Piezoelektrik, Adım Girdi, Darbe Girdi, Akıllı Kiriş, Sonlu Elemanlar Analizi olarak mühendislik uygulamalarında sıklıkla kullanılmaktadır. En yaygın kullanılan piezoelektrik malzeme kurşun-zirkonyumtitanyum (PZT) piezo seramiktir. Piezo seramikler karakteristik özelliklerine göre yumuşak ve sert olarak iki ana sınıfa ayrılırlar ve PZT-2, PZT-4, PZT-5A, PZT-5H, PZT-8 olarak isimlendirilirler. Bu çalışmada, akıllı bir kirişte farklı karakteristikti piezoelektrik algılayıcının dinamik cevapları sonlu elemanlar yöntemi kullanılarak ANSYS/Workbench programında incelenmiştir. Akıllı kiriș, alüminyum kiriș ile bir piezoelektrik algılayıcı ve bir piezoelektrik uyarıcıdan oluşmuştur. Akıllı kiriște hem uç noktasına tekil kuvvet, hem uyarıcıya voltaj, darbe ve adım girdiler şeklinde uygulanmıştır. Algılayıcı ve yer değiştirme sinyalleri dinamik analiz yapılarak elde edilmiştir. Akıllı kirişin piezoelektrik algılayıcı konumu ve karakteristiğine göre farklı dinamik cevaplar verdiği gözlemlenmiștir.

\section{Comparison of Dynamic Performance of Piezoelectric Sensors With Different Characteristic}

\section{Keywords}

Piezoelectric, Step Input, Impulse Input, Smart Beam, Finite Element Analysis

\begin{abstract}
Nowadays, piezoelectric materials have been widely used as a sensor or an actuator in engineering applications. The most commonly used piezoelectric material is lead-zirconatetitanium (PZT) ceramic. According to the characteristics, piezo ceramics are classified into two main classes, soft PZTs and hard PZTs, and they are called as PZT-2, PZT-4, PZT-5A, PZT-5H, PZT-8. In this work, dynamic responses of a piezoelectric sensor with different characteristics of a smart beam were investigated by using the finite element method in ANSYS/Workbench program. The smart beam was composed of an aluminum beam and a PZT sensor and a PZT actuator. Both a single force to the end point and
\end{abstract}


a voltage to the actuator were applied in the smart beam in the form of impulse and step inputs. Sensor and displacement signals were obtained by performing the dynamic analysis. It was observed that the smart beam has varied dynamic responses via the location and characteristic of piezoelectric sensor.

*Sorumlu yazar: levent.malgaca@deu.edu.tr

\section{Giriş}

Uzay, makine, elektronik gibi çeşitli mühendislik dalları için önemli kullanım alanına sahiptir. Piezo seramikler, radyo vericilerinde, telefon iletişim uygulamalarında, sonar ve ultrasonik cihazlar gibi teknolojik alanlarda kullanılır. En yaygın kullanım alanlarından biri algılayıcılardır. Piezo seramikler, uygulanan basınç altında elektriksel potansiyel (voltaj) oluşması ve elektriksel potansiyel uygulandığında ise yer değiştirme meydana gelmesi sebebiyle tersinir özeliğe sahiptir. $\mathrm{Bu}$ sebeple, piezo seramikler hem algılayıcı hem de uyarıcı olarak kullanılmaktadır.

En yaygın kullanılan piezo seramik kurşun-zirkonyum-titanyum seramiklerdir. Kullanılan diğer başlıca piezo seramikler; Kuvars (SiO2), Turmalin-baryum-titanat (BaTiO3), Çinko-oksit (ZnO) ve Poliviniliden-klorür (PVDF)'dir. Piezo seramikler, alüminyum, çelik ve kompozit malzemelerle birleştirilerek akıllı yapılar elde edilir. Akıllı yapılar ile ilgili çalışmalar kısaca özetlenmiştir.

Piezo seramiklerin teorik ve deneysel uygulamalarını aktif titreşim kontrolü çalışmalarında görmek mümkündür [14]. Akıllı yapıların modellenmesinde sonlu elemanlar yöntemi yaygın olarak kullanılmaktadır. Akıllı yapılarda piezo seramik uyarıcı ve algılayıcıların yerleşimi de çok önemlidir [5]. Kompozit akıllı kiriş ve plakaların titreşim kontrolü, çalışılan güncel konulardandır [6-8]. Kompozit akıllı plakalarda, piezo seramikler uyarıcı ve algılayıcı olarak kullanılarak plakadaki titreşimlerin, aktif ve pasif titreşim kontrolü gerçekleştirilmektedir. Piezo seramik uyarıcı ve alglayıcının aktif ve pasif titreşim kontrolündeki performansa etkisi incelenmektedir [9-11]. Titreşim kontrolü çalışmalarında farklı akıllı yapılar, farklı yöntemler kullanılmaktadır [12-13]. Piezo seramikler, uçak gövdelerinde meydana gelen çatlakların tespit edilmesinde ve çatlakların önlenmesinde de kullanılmaktadır [1415].

Farklı alanlardaki çalışmalara örnek olarak; piezo seramikler sağlı ve biyomedikal mühendislik alanlarındaki çalışmalarda, damar içerisindeki kanın akış hızının, nabzın belirlenmesinde ve takma el yapımında kullanılmaları, farklı alanlardaki çalıșmalara örnek olarak verilebilir [16]. Mekanik yapılarda çatlakların tespitinde piezo seramiklerin kullanımı söz konusudur [17].

Günümüzde piezoelektrik akıllı sistemlerin modellenmesinde ve dinamik analizlerinin gerçekleştirilmesinde çeşitli yöntemler kullanılmaktadır [18-19]. Ayrica, bu konuda ticari yazılımların kullanımları artarak devam etmektedir. $\mathrm{Bu}$ yazılımların en yaygın kullanılanları ANSYS ve ABAQUS ticari yazılımlarıdır [20-21].

Piezo seramik malzemeler, özelliklerine göre üretici firmalar tarafından sınıflandırmaktadırlar. Üreticiler, piezo seramikleri uyarıcı ve algılayıcı olarak kullanımı için önerilerde bulunmaktadırlar. $\mathrm{Bu}$ çalışmada, akıllı kirișe adım ve darbe girdileri uygulandı, farklı tip piezoelektrik algılayıcıların ve 
uyarıcıların bu girdilere performansı incelendi ve sayısal sonuçlar sunuldu. Beş farklı tip piezo seramik için algılayıcı ve uyarıcıların titreşim cevapları incelendi. Akıllı kiriște, alglayıcl mesafesinin algılayıcı performansına etkisi incelendi.

Piezo seramik uyarıcı ve algılayıcıdan oluşan bir akıllı kirişin modellenmesi ve dinamik benzetimi ANSYS/Workbench programı ile gerçekleştirilmiştir. Sonuçların irdelenmesi ve karşılaştırılması için MATLAB programı kullanılmıştır.

\section{Akıllı Kirişin Modellenmesi ve Benzetimi}

Piezoelektrik malzemelerin modellenmesinde kullanılan denklemler aşağıda verilmiştir [22].

$$
\begin{aligned}
& \{T\}=[c]\{S\}-[e]\{E\} \\
& \{D\}=\left[e^{T}\right]\{S\}+[\varepsilon]\{E\}
\end{aligned}
$$

Burada mekanik değişkenlerden $\mathrm{T}$ ve $\mathrm{S}$ sırasıyla gerilme ve şekil değiștirme vektörleridir. Elektriksel değişkenlerden D ve E sırasıyla elektrik yer değiștirmesi ve elektrik alan vektörleridir. [c], [e] ve [ع] matrisleri piezoelektrik malzeme özellikleridir. [c] elastisite, [e] piezoelektrik, $[\varepsilon]$ dielektrik matrisleridir.
Akıllı kiriş için hareket denklemleri aşağıdaki gibi ifade edilebilir.

$$
\begin{aligned}
& {[M]\{\ddot{u}\}+[C]\{\dot{u}\}+[K]\{u\}+\left[K^{Z}\right]\{V\}=\{F\}} \\
& {\left[K^{Z}\right]^{T}\{u\}+\left[K^{d}\right]\{V\}=\{L\}}
\end{aligned}
$$

Burada, [M], [C] ve [K] sirasiyla akıllı kirișin kütle, sönüm ve direngenlik matrisidir. $\left[\mathrm{K}^{\mathrm{Z}}\right]$ piezoelektrik matrisinden hesaplanan piezoelektrik direngenlik matrisidir. $\left[\mathrm{K}^{\mathrm{d}}\right]$ dielektrik matrisinden hesaplanan dielektrik direngenlik matrisidir. $\{\mathrm{u}\}$ ve $\{\mathrm{V}\}$ sırasıyla dügüm yer değiştirmesi ve elektriksel potansiyeldir. $\{F\}$ ve $\{L\}$ ise sirasiyla kuvvet ve elektriksel yüktür.

Akıllı kirişin modellenmesi ve dinamik analizleri için ANSYS/Workbench yazılımı kullanılmıştır. Çalışmada dikkate alınan akıllı kiriş Şekil 1'de gösterilmiştir.

Akıllı kirişin boyu, eni ve kalınlığı sırasıyla $600 \times 20 \times 2 \mathrm{~mm}^{3}$ dir. Piezo seramiklerin boyu, eni ve kalınlığı sırasıyla 25 × 20 × 1 $\mathrm{mm}^{3}$ dir. Piezo seramik algılayıcı ve uyarıcının ankastre uçtan mesafesi $\mathrm{Ls}_{\mathrm{s}}$ parametresi ile gösterilmiştir.

Akıllı kiriș ait alüminyum malzeme ile PZT2, PZT4, PZT5A, PZT5H ve PZT8 piezo seramik malzemeler için özellikler Tablo 1 'de verilmiştir.

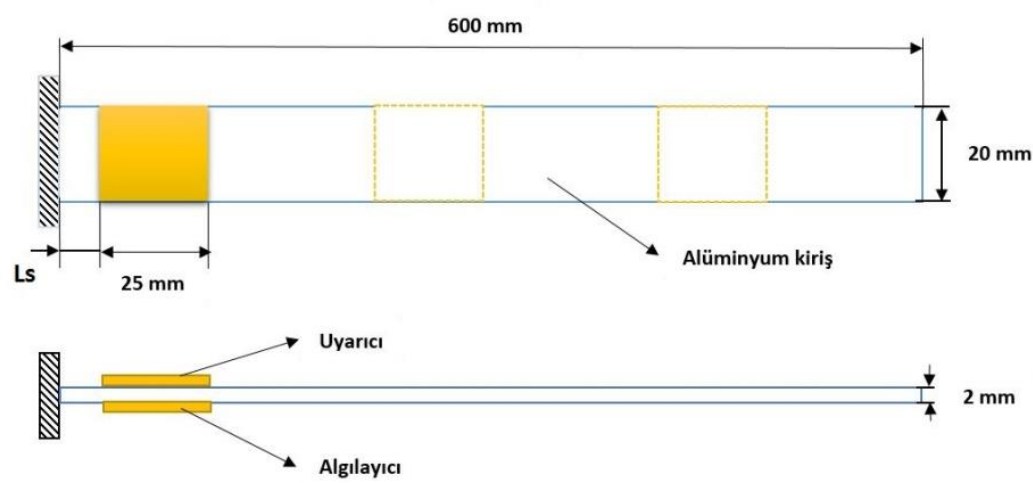

Şekil 1. Akıllı kirişin konfigürasyonu 
Tablo 1. Alüminyum kiriş ve piezo seramik malzeme özellikleri

\begin{tabular}{|c|c|c|c|c|c|c|}
\hline & $\begin{array}{l}\text { Alüminyum } \\
\text { Kiriș }\end{array}$ & PZT-2 & PZT-4 & PZT-5A & PZT-5H & PZT-8 \\
\hline $\begin{array}{l}\text { Elastisite } \\
\text { Modülü } \\
\left(\mathrm{N} / \mathrm{m}^{2}\right)\end{array}$ & $69 \times 10^{10}$ & - & - & - & - & - \\
\hline $\begin{array}{l}\text { Yoğunluk } \\
\left(\mathrm{kg} / \mathrm{m}^{3}\right)\end{array}$ & 2676 & 7600 & 7500 & 7750 & 7500 & 7600 \\
\hline $\begin{array}{l}\text { Poisson } \\
\text { Oranı }\end{array}$ & 0.32 & - & - & - & - & - \\
\hline \multicolumn{7}{|c|}{ Sabit elektrik alanda elastik rijitlik matrisi $\left(\mathrm{N} / \mathrm{m}^{2}\right)$} \\
\hline $\mathrm{C}_{11}$ & & $158.33 \times 10^{9}$ & $138.9 \times 10^{9}$ & $120.3 \times 10^{9}$ & $126.0 \times 10^{9}$ & $146.8 \times 10^{9}$ \\
\hline $\mathrm{C}_{12}$ & & $69.05 \times 10^{9}$ & $77.83 \times 10^{9}$ & $75.18 \times 10^{9}$ & $79.5 \times 10^{9}$ & $81.08 \times 10^{9}$ \\
\hline $\mathrm{C}_{13}$ & & $67.46 \times 10^{9}$ & $74.28 \times 10^{9}$ & $75.09 \times 10^{9}$ & $84.1 \times 10^{9}$ & $81.05 \times 10^{9}$ \\
\hline $\mathrm{C}_{33}$ & & $149.9 \times 10^{9}$ & $115.4 \times 10^{9}$ & $110.8 \times 10^{9}$ & $117.0 \times 10^{9}$ & $131.7 \times 10^{9}$ \\
\hline $\mathrm{C}_{44}$ & & $45.045 \times 10^{9}$ & $30.58 \times 10^{9}$ & $22.57 \times 10^{9}$ & $23.3 \times 10^{9}$ & $32.9 \times 10^{9}$ \\
\hline \multicolumn{7}{|c|}{ Piezoelektrik uzama matrisi (C/m²) } \\
\hline $\mathrm{E}_{31}$ & & -3.13 & -5.20 & -5.35 & -6.5 & 9.8 \\
\hline $\mathrm{E}_{33}$ & & 14.51 & 15.08 & 15.78 & 23.3 & 23.6 \\
\hline $\mathrm{E}_{15}$ & & 10.90 & 12.71 & 12.29 & 17 & 10.3 \\
\hline \multicolumn{7}{|c|}{ Sabit uzamada dielektrik matrisi (F/m) } \\
\hline$\varepsilon_{11}$ & & $8.85 \times 10^{-9}$ & $6.46 \times 10^{-9}$ & $8.11 \times 10^{-9}$ & $15.03 \times 10^{-9}$ & $7.96 \times 10^{-9}$ \\
\hline$\varepsilon_{22}$ & & $8.85 \times 10^{-9}$ & $6.46 \times 10^{-9}$ & $8.11 \times 10^{-9}$ & $15.03 \times 10^{-9}$ & $7.96 \times 10^{-9}$ \\
\hline$\varepsilon_{33}$ & & $8.05 \times 10^{-9}$ & $5.62 \times 10^{-9}$ & $7.34 \times 10^{-9}$ & $13.0 \times 10^{-9}$ & $5.31 \times 10^{-9}$ \\
\hline
\end{tabular}

Tablodaki piezo seramik malzeme özellikleri aynı zamanda üretici olan MORGAN firmasına aittir [23]. Malzeme özellikleri farklı üreticiler için farklılık göstermektedir. Üretici firmaların piezo seramik malzeme özelliklerini matris formunda vermeleri, sonlu elemanlar yöntemiyle analiz süreçlerinde önemli kolaylık sağlamaktadır. Matris formunda verilmeyen malzeme özellikleri, piezoelektrik teorisindeki formüller kullanılarak matris formuna dönüştürülebilir $[10,22]$. Bu dönüşüm için formüllerde ihtiyaç duyulan tüm verilerin, üretici tarafından sağlanması gerekir. Üretici verisinde eksik olması durumunda, malzeme özellikleri bazı kabullere dayalı olarak matris formuna çevrilebilmekte, fakat doğrulama çalışmalarında güçlükler yaşanmaktadır.

Akıllı kiriş modeli için ilk aşamada alüminyum kirişin ve piezoelektrik algılayıcı ile uyarıcının üç boyutlu katı modeli oluşturulmuștur. Daha sonra, metal kısım için SOLID186, piezo seramikler için SOLID226 elemanları kullanılarak sonlu elemanlar modeli oluşturulmuştur. Akıllı kirişin sonlu elemanlar modeli Şekil 2'de gösterilmiştir.

Her iki eleman da 20 düğüm noktasına ve $\mathrm{x}$, y ve $\mathrm{z}$ de ötelemeye sahipken, SOLID226 farklı olarak voltaj serbestlik derecesine de sahiptir. Akıllı kirişin sonlu elemanlar modeli, toplam 455 eleman ve 1820 düğüm noktasından oluşmaktadır. Her piezo seramik sonlu eleman modeli, 79 eleman ve 316 düğüm noktasına sahiptir. Akıllı kirişin sonlu elemanlar modelinde, $B$ ve $D$ yüzeyleri alüminyum kirișe ait, $A$ ve $C$ yüzeyleri piezo seramik algılayıcıya ve $E$ ve $F$ yüzeyleri ise piezo seramik uyarıcıya ait yüzeylerdir. Piezo seramiklerin A ve F yüzeylerine adım ve darbe voltaj girdi uygulanmakta olup, $\mathrm{C}$ ve E yüzeylerine topraklama yapılmıștır. 


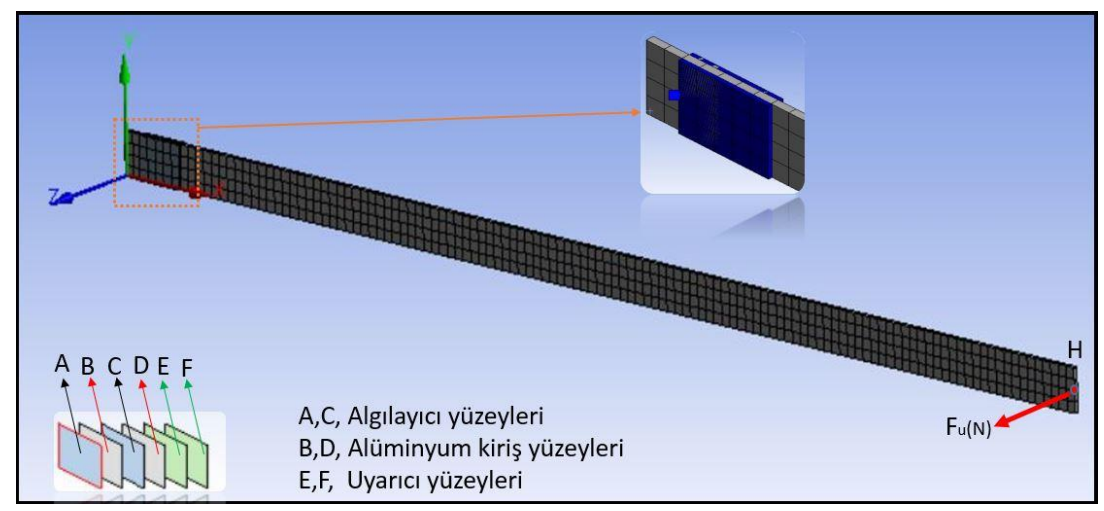

Şekil 2. Akıllı kirișin sonlu eleman modeli

Şekil 2'deki H noktasına ise, kuvvet darbe ve adım girdi tipinde kuvvet uygulanmıştır.

Piezoelektrik malzemeler, uygulanan kuvvet etkisiyle şekil değiştirirler ve bu şekil değişiminden dolayı elektriksel potansiyel sağlarlar. $\mathrm{Bu}$ algılayıcı prensibidir. Akıllı yapılarda piezo seramik algılayıcıların yerleștirileceği noktalar önemlidir ve yapıdaki maksimum uzamanın olduğu noktalara yerleştirilmektedir $[10,24]$. Ankastre akıllı kirişte, maksimum uzamanın ankastre uçta olduğu bilinmektedir.

Piezo seramik algılayıcının, akıllı kiriște yerleștirildiği konumun, algılayıcı performansına etkisini inceleyebilmek için üç farklı algılayıcı konumu dikkate alınmıştır. İlk durumda akıllı kirişte algılayıcı ve uyarıcı ankastre uçtan eşit ve $\mathrm{L}_{\mathrm{s}}=10 \mathrm{~mm}$ mesafede yerleştirilmiştir. Daha sonra uyarıcının ankastre uçtan $\left(\mathrm{L}_{\mathrm{s}}=10 \mathrm{~mm}\right)$ mesafesi korunarak, algılayıcı ankastre uçtan $L_{s}=185 \mathrm{~mm}$ ve $\mathrm{L}_{\mathrm{s}}=360 \mathrm{~mm}$ mesafede yerleștirilerek analizler yapılmıştır.
$\mathrm{Bu}$ çalışmadaki akıllı kirişin sonlu elemanlar modelinin doğruluğunu test etmek için Tablo 3'te verilen literatür 'deki kaynak çalışmalar dikkate alınmıştır. Tablo 3'teki kaynak çalışmalarda dikkate alınan akıllı kiriş boyutu ve algılayıcı/uyarıcı boyutları ile algılayıcının/uyarıcının kiriş üzerindeki ankastre uçtan olan yerleștirme mesafelerini açlklar. Tablo 3'teki çalışmalarda kullanılmış piezoelektrik malzeme tipi PZT-5H'dir.

Doğal frekans sonuçlarını karşılaştırmak için Tablo 3'te verilen piezoelektrik algılayıcı/uyarıcı içeren akıllı kirişlerin sonlu eleman modelleri ANSYS/Workbench programinda kurulmuştur. Daha sonra frekans analizleri yapılarak doğal frekansları hesaplanmıștır. Tablo 4'te referans çalışmalarda verilen birinci doğal frekans sonuçları ile kurulan benzetim modellerinden elde edilen birinci doğal frekans sonuçları karşılaştırılmıştır.

Tablo 2. Güncel çalışmanın doğal frekansları

\begin{tabular}{cccccc}
\hline & \multirow{2}{*}{ PZT2 } & PZT4 & PZT5A & PZT5H & \multirow{2}{*}{ PZT8 } \\
\hline $\mathrm{f}_{1}$ & 4.9265 & 4.9141 & 4.9009 & 4.9023 & 4.9138 \\
$\mathrm{f}_{2}$ & 30.555 & 30.480 & 30.402 & 30.410 & 30.478 \\
$\mathrm{f}_{3}$ & 47.776 & 47.522 & 47.280 & 47.299 & 47.487 \\
\hline
\end{tabular}


L. Malgaca vd. / Farklı Karakteristikli Piezoelektrik Algılayıcıların Dinamik Performanslarının Karşılaştırılması

Tablo 3. Kaynak çalışmalardaki modellerin boyutları

\begin{tabular}{ccccc}
\hline Kaynaklar & Kirişin, $\mathrm{mm}^{3}$ & $\begin{array}{l}\text { Alglayıcl, } \\
\mathrm{mm}^{3}\end{array}$ & Uyarıcl, $\mathrm{mm}^{3}$ & $\begin{array}{c}\text { Alglayıcı ve uyarıcl } \\
\text { mesafesi, mm }\end{array}$ \\
\hline$[3]$ & $507 \times 51 \times 2$ & $20 \times 25 \times 0.61$ & $20 \times 25 \times 0.61$ & 5 \\
{$[4]$} & $350 \times 24 \times 1$ & $72 \times 24 \times 0.5$ & $72 \times 24 \times 0.5$ & 0 \\
{$[25]$} & $508 \times 25.4 \times 0.8$ & $27 \times 13 \times 0.028$ & $76.2 \times 25.4 \times 0.305$ & 50.9 \\
{$[26]$} & $226 \times 25 \times 0.965$ & $39 \times 25 \times 0.75$ & $39 \times 25 \times 0.75$ & 10 \\
\hline
\end{tabular}

Tablo 4. Doğal frekansların kaynak çalışmalarla karşılaştırılması

\begin{tabular}{ccc}
\hline Kaynaklar & Kaynak çalışma $\mathrm{f}_{1}(\mathrm{~Hz})$ & Benzetim $\mathrm{f}_{1}(\mathrm{~Hz})$ \\
\hline$[3]$ & 6.67 & 6.600 \\
{$[4]$} & 3.11 & 3.040 \\
{$[25]$} & 19.85 & 19.948 \\
{$[26]$} & 9.00 & 9.0046 \\
\hline
\end{tabular}

Tablo 4'te görüldüğü gibi sonuçların iyi eşleştiği gözlenmiştir. Sonra bu çalışmadaki titreşim analizine devam edilmiștir. Dinamik analizde zaman adımının belirlenmesi için akıllı kirişin doğal frekanslarından faydalanılır. Dinamik analizlerde zaman adımı için ilk üç titreşim biçimi dikkate alınarak $\mathrm{d}_{\mathrm{t}}=1 / \mathrm{f}_{3} / 20$ formülü ile hesaplanmıştır.

Dinamik analiz benzetimleri için Şekil 2'de gösterildiği gibi akıllı kirișin $\mathrm{H}$ noktasına kuvvet ve F yüzeyine ise voltaj girdileri uygulanarak dört farklı durum incelenmiştir. İlk iki durumda adım ve darbe şeklinde kuvvet girdileri akıllı kirişin serbest ucuna, üçüncü ve dördüncü durumda ise adım ve darbe şeklinde voltaj girdileri uyarıcıya uygulanmiștır. Darbe girdilerin şiddeti $0.001 \mathrm{~N}$ ve $50 \mathrm{~V}$ olacak şekilde ikizkenar üçgen şeklinde sayısal olarak modellenmiştir. Kuvvet için darbe ve adım girdileri Şekil 3'de gösterilmiştir.

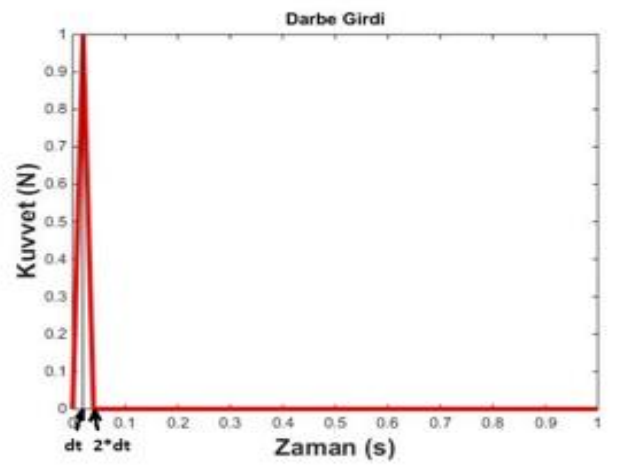

a.

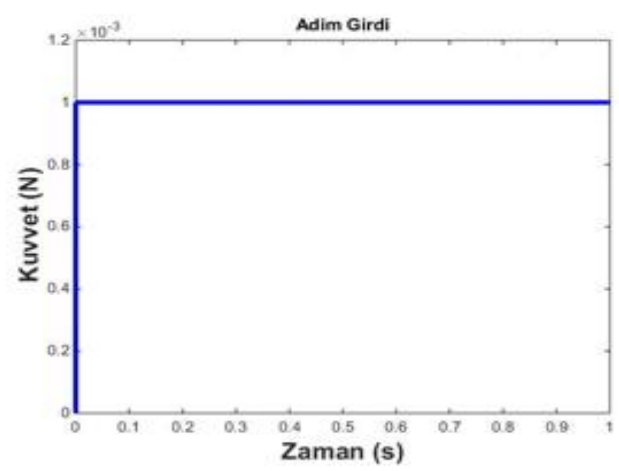

b.

Şekil 3. a) Kuvvet darbe girdi, b) Kuvvet adım girdi. 

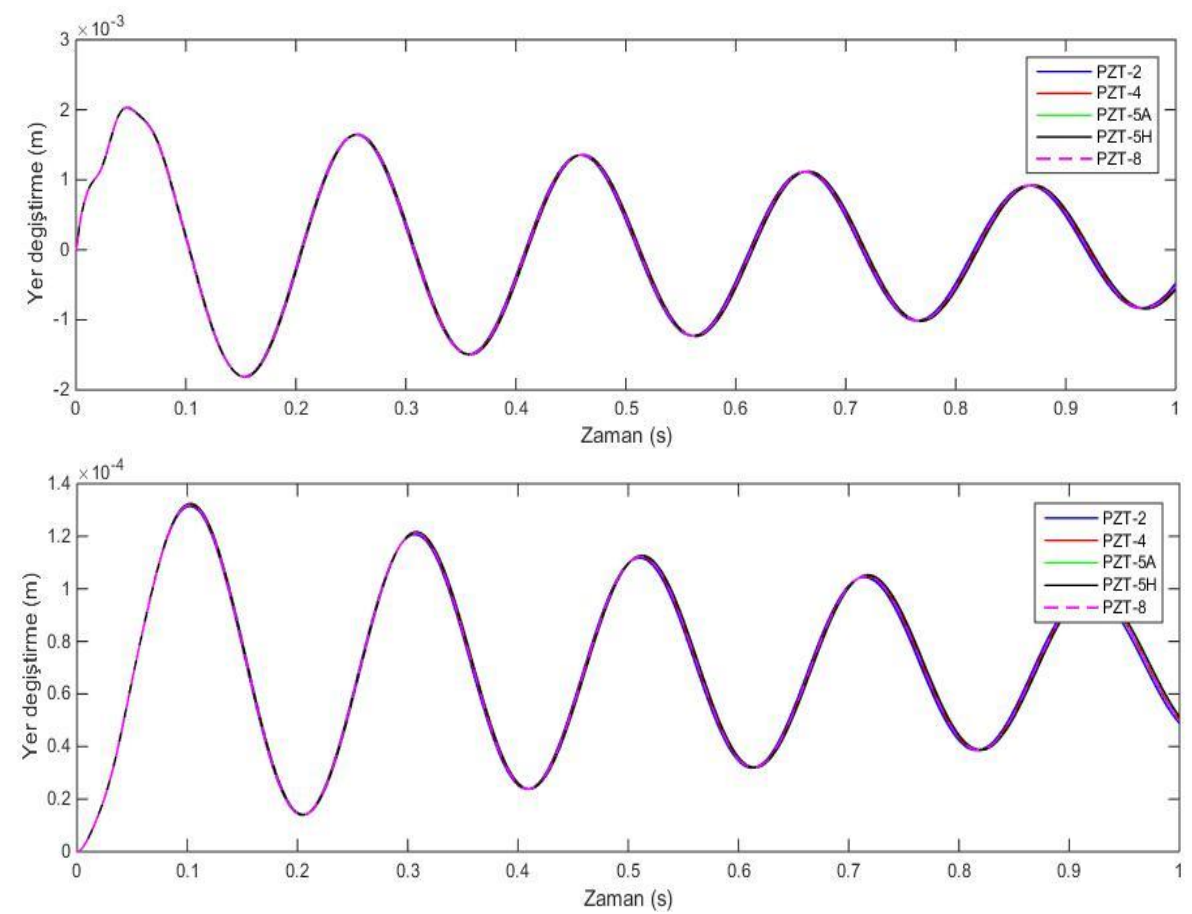

Şekil 4. Akıllı kirişin darbe ve adım kuvvet girdisine dinamik cevapları
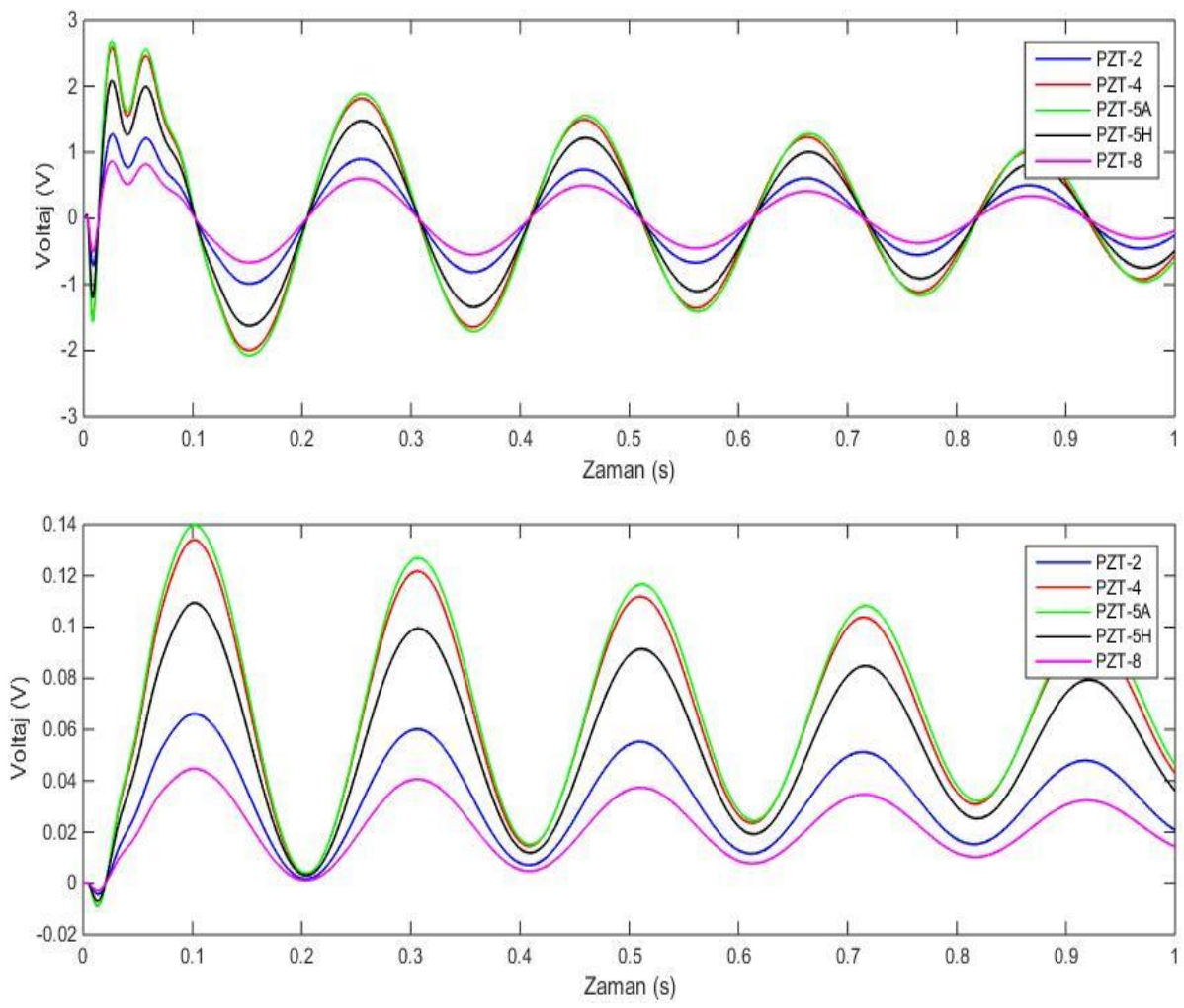

Şekil 5. Algılayıcının darbe ve adım kuvvet girdisine dinamik cevapları 

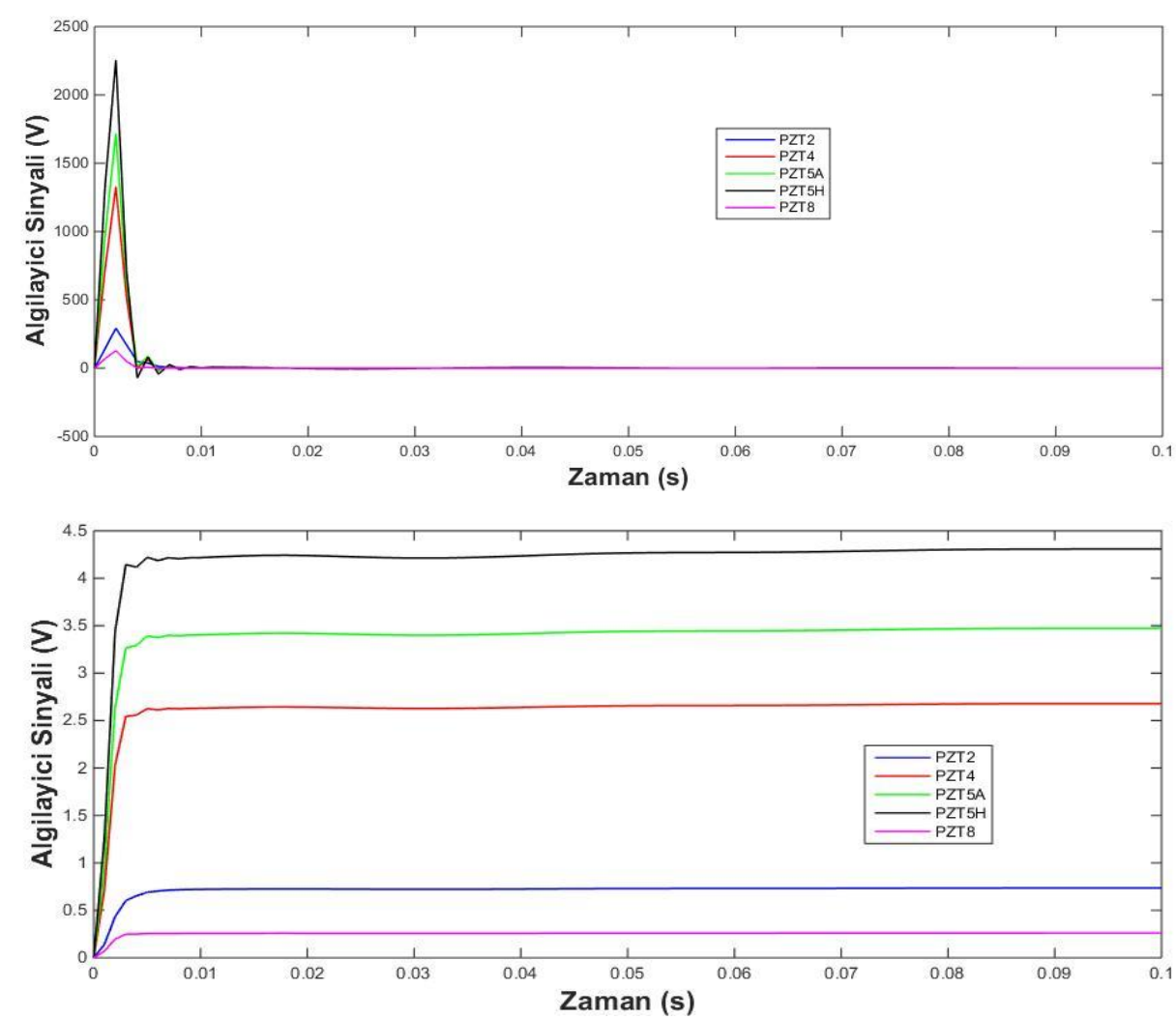

Şekil 6. Algılayıcının darbe ve adım voltaj girdisine dinamik cevapları

Farklı piezo seramikler için akıllı kirişin darbe ve adım şeklindeki kuvvet ve voltaj girdilerine dinamik cevapları Şekil 4-6’de gösterilmiştir.

Şekil 4, darbe ve adım kuvvet girdilerine uç noktanın yer değiştirme cevabı, Şekil 5 ise algılayıcının dinamik cevabıdır. Şekil 4'den görüldüğü gibi farklı karakteristikli piezo seramiklerin yer değiștirme cevabına önemli bir etkisi yoktur. Şekil 5 'den görüldüğü gibi farklı karakteristikli piezo seramikler algllayıcı dinamik cevaplarında farklı sonuçlar vermektedir.

Şekil 6'de ise uyarıcıya darbe ve adım voltaj girdileri uygulandığında elde edilen algılayıcının dinamik cevapları gösterilmiştir. Kuvvet girdilerine dinamik algılayıcı cevaplarında en büyük genliklerin PZT-5A için voltaj girdilerine dinamik algılayıcı cevaplarında en büyük genliklerin PZT-5H için elde edildiği gözlemlenmiştir. Hem kuvvet hem de voltaj girdilerine dinamik algılayıcı cevaplarında en küçük genliklerin PZT-8 için elde edildiği gözlemlenmiştir. Şekil 46'deki sonuçların daha net değerlendirilmesi için girdilere karşı oluşan dinamik cevaplardaki mutlak değerce maksimum değerler Tablo 5'de sunulmuştur. Tabloda, darbe ve adım girdilere karşılık algılayıcıda meydana gelen maksimumu voltaj değeri $V_{\max }$, akıllı kirişin uç noktasında meydana gelen maksimum yer değiştirme $\mathrm{d}_{\max }$ ile gösterilmiştir. 
Tablo 5. Dinamik girdilere maksimum sonuçlar

\begin{tabular}{cccccc}
$\mathrm{L}_{\mathrm{s}}=10 \mathrm{~mm}$ & & $\begin{array}{c}50 \mathrm{~V} \text { Darbe } \\
\text { girdi }\end{array}$ & $\begin{array}{c}50 \mathrm{~V} \text { Adım } \\
\text { girdi }\end{array}$ & $\begin{array}{c}0.001 \mathrm{~N} \text { Darbe } \\
\text { girdi }\end{array}$ & $\begin{array}{c}0.001 \mathrm{~N} \text { Adım } \\
\text { girdi }\end{array}$ \\
& & & & & \\
\hline \multirow{2}{*}{ PZT-2 } & $\mathrm{V}_{\max }(\mathrm{V})$ & 292.83 & 0.7353 & 1.2740 & 0.0661 \\
& $\mathrm{~d}_{\max }(\mathrm{m})$ & $3.806 \times 10^{-4}$ & $2.004 \times 10^{-5}$ & 0.00202 & 0.000131 \\
& $\mathrm{~V}_{\max }(\mathrm{V})$ & 1328 & 2.678 & 2.5863 & 0.1340 \\
PZT-4 & $\mathrm{d}_{\max }(\mathrm{m})$ & $7.79 \times 10^{-4}$ & $4.003 \times 10^{-5}$ & 0.00203 & 0.000131 \\
& $\mathrm{~V}_{\max }(\mathrm{V})$ & 1717.3 & 3.473 & 2.6813 & 0.1396 \\
PZT-5A & $\mathrm{d}_{\max }(\mathrm{m})$ & $1.069 \times 10^{-3}$ & $5.372 \times 10^{-5}$ & 0.00203 & 0.000132 \\
& $\mathrm{~V}_{\max }(\mathrm{V})$ & 2255.2 & 4.308 & 2.0859 & 0.1094 \\
PZT-5H & $\mathrm{d}_{\max }(\mathrm{m})$ & $1.899 \times 10^{-3}$ & $8.349 \times 10^{-5}$ & 0.00203 & 0.000132 \\
& $\mathrm{~V}_{\max }(\mathrm{V})$ & 128.21 & 0.261 & 0.8660 & 0.0447 \\
PZT-8 & $\mathrm{d}_{\max }(\mathrm{m})$ & $2.380 \times 10^{-4}$ & $1.269 \times 10^{-5}$ & 0.00202 & 0.000131 \\
& & & & & \\
\hline
\end{tabular}

Farklı karakteristikli piezo seramiklerin yer değiştirme sonuçlarını etkilemediği, ancak algılayıcı performansını önemli ölçüde değiştirdiği Tablo 5'ten görülmüştür. Ayrıca PZT-5A ve PZT5 H'nın algılayıcı seçiminde belirgin şekilde tercih edilebileceği gözlemlenmiştir.

Ayrıca akıllı kiriş üzerinde algılayıcının konumunun dinamik performansa etkisi de araștırılmıștır. Bu amaç için algılayıcı mesafesi yukarıda açıklandığı ve Şekil
1 'de gösterildiği gibi değiștirilmiştir. Şekil 4-6'deki sonuçlar $L_{s}=10 \mathrm{~mm}$ için elde edilmiştir. Mesafe değişiminin etkisi için yukarıda elde edilen sonuçların değerlendirilmesi sonucunda iki algılayıcının performansını inceleyebilmek için, uyarıcıya darbe ve adım voltaj girdi uygulandığında PZT-5A ve $H$ noktasına darbe ve adım kuvvet girdi uygulandığında PZT-5H dikkate alınmıştır. Algılayıcı mesafesinin değişiminin algılayıcı performansına etkisi Tablo 6'da verilmiştir.

Tablo 6. PZT-5A ve PZT 5H için algılayıcı mesafesinin algılayıcı performansına etkisi

\begin{tabular}{lllllllll}
\hline & \multicolumn{9}{c}{ PZT-5A } & \multicolumn{3}{c}{ PZT-5H } \\
\cline { 2 - 9 } $\begin{array}{l}\text { Ls } \\
(\mathrm{mm})\end{array}$ & $\begin{array}{l}0.001 \mathrm{~N} \text { Darbe } \\
\text { girdi }\end{array}$ & \multicolumn{3}{c}{$0.001 \mathrm{~N}$ Adım girdi } & \multicolumn{2}{c}{ 40 V Darbe girdi } & 40 V Adım girdi \\
& $\begin{array}{l}\mathrm{V}_{\max } \\
(\mathrm{V})\end{array}$ & $\mathrm{d}_{\max }(\mathrm{m})$ & $\mathrm{V}_{\max }(\mathrm{V})$ & $\mathrm{d}_{\max }(\mathrm{m})$ & $\begin{array}{l}\mathrm{V}_{\max } \\
(\mathrm{V})\end{array}$ & $\mathrm{d}_{\max }(\mathrm{m})$ & $\mathrm{V}_{\max }(\mathrm{V})$ & $\mathrm{d}_{\max }(\mathrm{m})$ \\
\hline 10 & 3.460 & 0.00203 & 0.04647 & 0.000132 & 1782.3 & $1.38 \times 10^{-3}$ & 3.447 & $6.67 \times 10^{-5}$ \\
185 & 3.078 & 0.00201 & 0.02118 & 0.000129 & 45.57 & $2.35 \times 10^{-3}$ & 0.0854 & $1.12 \times 10^{-4}$ \\
360 & 1.156 & 0.00196 & 0.00976 & 0.000133 & 24.25 & $2.35 \times 10^{-3}$ & 0.0680 & $1.12 \times 10^{-4}$ \\
\hline
\end{tabular}


Algılayıcı performansının ankastre uca yakınlaştıkça arttığı gözlenmektedir. Ankastre kiriște maksimum uzamanın sabit uca yaklaştıkça artmasının bilinmesi, algılayıcı performansının değişiminin nedeni olarak açıklanabilir. Buna göre farklı sınır şartlarına sahip akıllı yapılarda algılayıcının konumlandırılmasında ve piezo seramik malzeme seçiminde bu önemli hususların göz önünde bulundurulması önem kazanmaktadır.

\section{Sonuçlar}

Çalışmanın ilk kısmında farklı karakteristikli piezo seramik algılayıcı ve uyarıcıdan oluşan ankastre akıllı kirişin sonlu elemanlar modeli olușturulmuştur. Akıllı kirișin doğal frekansları bulunarak aynı zamanda doğrulama çalışması için frekans sonuçları kaynak çalışmalarla karşılaştırılmıştır. Akıllı kirişin uç noktasına kuvvet, uyarıcıya ise voltaj adım ve darbe girdi şeklinde uygulanmıştır. Akıllı kirişin uç noktasında oluşan dinamik yer değiștirmeler ve piezo seramik algılayıcıda oluşan dinamik voltaj değişimleri elde edilmiştir. Farklı karakteristikli piezo seramik algılayıcıların dinamik davranışları incelenmiştir. Akıllı kiriş üzerinde algılayıcının konumunun dinamik performansa etkisi de araştırılmıştır. Farklı karakteristikli piezo seramiklerin yer değiştirme sonuçlarını etkilemediği, ancak algılayıcı performansını önemli ölçüde değiştirdiği gözlemlenmiştir. Elde edilen sonuçlar değerlendirildiğinde, algılayıcı seçiminde PZT-5A ve PZT$5 H^{\prime}$ ın tercih edilebileceği ortaya konulmuştur.

\section{Kaynakça}

[1] Loghmani, A., Danesh, M., Keshmiri, M., Savadi, M. M. 2015. Theoretical and Experimental Study of Active Vibration Control of a Cylindrical
Shell Using Piezoelectric Disks, Journal of Low Frequency Noise, Vibration and Active Control, Cilt. 34-3, s. 269-288.

[2] Dafang, W., Liang, H., Bing, P., Yuewu, W., Shuang, W. 2014. Experimental study and numerical simulation of active vibration control of a highly flexible beam using piezoelectric intelligent material, Aerospace Science and Technology, Cilt. 37(2014), s. 1019.

[3] Yaman, Y., Çalışkan, T., Nalbantoğlu, V., Prasad, E., Waechter, D. 2002. Active vibration control of a smart beam, 6th CanSmart symposium, Montreal.

[4] Manning, W. J., Plummer, A. R., Levesley, M. C. 2000. Vibration control of a flexible beam with integrated actuators and sensors, Smart Materials Structures, Cilt. 9, s. 932-9.

[5] Kumar, K. R., Narayanan. S. 2008. Active vibration control of beams with optimal placement of piezoelectric sensor/actuator pairs, Smart Materials Structures, Cilt. 17(2008), 055008 doi:10.1088/0964726/17/5/055008.

[6] Li, F., Lyu, F. 2014. Active vibration control of lattice sandwich beams using the piezoelectric actuator/sensor pairs, Composites: Part B, Cilt. 67(2014), s. 571-578.

[7] Zippo, A., Ferrari, G., Amabili, M., Barbieri, M., Pellicano, F. 2015. Active vibration control of a composite sandwich plate, Composite Structures, Cilt. 128(2015), s. 100-114.

[8] Malgaca, L. 2010. Integration of Active Vibration Control Methods with Finite Element Models of Smart Laminated Composite Structures. Composite Structures, Cilt. 92(2010), s.1651-1663. 
[9] Tsushima, N., Su, W. 2017. Flutter suppression for highly flexible wings using passive and active piezoelectric effects, Aerospace Science and Technology, Cilt. 65(2017), s. 78-89.

[10] Chopra, I., Sirohi, J. 2013. Smart Structures Theory, Cambridge University Press, New York, USA.

[11] Malgaca L., Uyar, M., Yavuz, Ș. 2017. Active vibration suppression of a single-link smart flexible manipulator, International Journal of Natural and Engineering Sciences, Cilt. 11(1), s. 13-19.

[12] Vashist, S. K., Chhabra, D. 2014. Optimal placement of piezoelectric actuators on plate structures for active vibration control using genetic algorithm, Proc. SPIE 9057, Active and Passive Smart Structures and Integrated Systems Cilt. 905720, 9 Mart 2014. doi:0.1117/12.2044904;https://do i.org/10.1117/12.2044904.

[13] Ferrari, G., Amabili, M. 2015. Active vibration control of a sandwich plate by non-collocated positive position feedback, Journal of Sound and Vibration, Cilt. 342(2015), s. 44-56.

[14] Ihn, J., Chang, F. 2004. Detection and monitoring of hidden fatigue crack growth using a built-in piezoelectric sensor/actuator network: II. Validation using riveted joints and repair patches, Smart Materials Structures, Cilt. 13 (2004), s. 621-630. doi: 10.1088/0964-1726/13/3/021.

[15] Zhao, X., Gao, H., Zhang, G., Ayhan, B., ChimanKwan, F. Y., Rose, J. L. 2007. Active health monitoring of an aircraft wing with embedded piezoelectric sensor/actuator network: I. Defect detection, localization and growth monitoring, Smart Materials Structures, Cilt. 16(2007), s. 1208-1217. doi:10.1088/09641726/16/4/032.

[16] Cotton, D. P. J., Chappell, P. H., Cranny, A., White, N. M., Beeby, S. B. 2007. A Novel Thick-Film Piezoelectric Slip Sensor for a Prosthetic Hand, IEEE sensors journal, Cilt. 7, no. 5, Mayıs 2007. doi: 10.1109/JSEN.2007.894912.

[17] Patil, C. S., Roy, S., Jagtap, K. R. 2017. Damage Detection in Frame Structure Using Piezoelectric Actuator, 5th International Conference of Materials Processing and Characterization (ICMPC 2016), Materials Today: Proceedings, Cilt. 4(2017), s. 687692.

[18] Elshafei, M. A., Alraiess, F. 2013. Modeling and analysis of smart piezoelectric beams using simple higher order shear deformation theory, Smart Materials and Structures, Cilt. 22(2013), s. 035006 (14pp).

[19] Park, I., Lee, U. 2012. Dynamic analysis of smart composite beams by using the frequency-domain spectral element method, Journal of Mechanical Science and Technology, Cilt. 26(8), s. 25112521.

[20] ANSYS Software, 2016. ANSYS, Inc. Erişim Adresi: http://www.ansys.com (Erişim tarihi: 22.08.2016).

[21] ABAQUS Software, 2016. ABAQUS UNIFIED FEA. Erişim Adresi: http://www.3ds.com/productsservices/simulia/products/abaqus / (Erişim Tarihi:22.08.2016).

[22] Preumont, A. 2011. Vibration Control of Active Structures: An Introduction, Springer Netherlands.

[23] Morgan Company, 2016. Products, Erişim Adresi: http://www.morgantechnicalcera mics.com/ (Erişim Tarihi: 22.08.2016) 
L. Malgaca vd. / Farklı Karakteristikli Piezoelektrik Algılayıcıların Dinamik Performanslarının Karşılaştırılması

[24] Braunt, I., Coffignal, G., Lene, F. 2001, A methodology for determination of piezoelectric actuator and sensor location on beam structures, Journal of Sound and Vibration, Cilt. 5(2001), s. 861882. doi:10.1006/jsvi.2000.3448.

[25] Yousefi-Koma, A. 1997. Active vibration control of smart structures using piezo elements, $\mathrm{PhD}$ Thesis, Carleton University, Ottawa, Ontario.

[26] Xu, S. X., Koko, T. S. 2002. Finite element analysis and design of actively controlled piezoelectric smart structures, Finite Element Analysis and Design, Cilt. 40(2004), s. 241-62. 